\title{
Fenomenologia e raciocínio clínico em psiquiatria: o conceito de marcadores psicopatológicos
}

\author{
Gustavo Fernando Julião de Souza ${ }^{1}$
}

\section{Resumo}

O presente artigo corresponde ao produto final de múltiplas reflexões teóricas que se sucederam ao longo de quase vinte anos de supervisão de casos clínicos no ambulatório da Residência de Psiquiatria do Hospital das Clínicas da UFMG e, também, no decorrer de longa prática clínica em outros ambulatórios, hospitais e consultório privado por mais de trinta anos de trabalho diário. Dessa maneira, o autor propõe a utilização de um método de investigação semiológica, denominado por ele de fenomenológico-dinâmico, resultando em um 'constructo' teórico - no qual a personalidade pré-mórbida é componente importante - capaz de viabilizar hipóteses diagnósticas que se mostrem acertadas, precisas e detalhadas na prática clínica. Para ilustrar a utilidade prática do método proposto, apresenta quatro casos clínicos nos quais o utiliza e estabelece os conceitos de "morbus" primário e secundário, filtro ou prisma caracterológico e marcadores psicopatológicos. Além disso, cita e revisa outros conceitos teóricos estabelecidos em artigos anteriores, tais como transtorno ou estado psicoide.

Palavras-chave: Fenomenologia; Personalidade pré-mórbida; Transtornos de Personalidade; Marcadores psicopatológicos; Psicoses atípicas.

\footnotetext{
${ }^{1}$ Médico psiquiatra. Preceptor da Residência de Psiquiatria do Hospital das Clínicas da UFMG (aposentado). Professor dos cursos de graduação da Faculdade de Ciências Médicas de Minas Gerais (FCMMG) e da Faculdade de Medicina da UFMG (aposentado). Vice-Presidente da Associação Acadêmica Psiquiátrica de Minas Gerais (AAPMG). Email: gustavojuliaodesouza@yahoo.com.br.www.gustavojuliao.med.br
} 


\title{
Phenomenology and clinical reasoning in psychiatry: the concept of psychopathological markers
}

\begin{abstract}
This article derives from the hard work resulted from multiple theoretical reflections, gradually constructed during twenty years of direct contact with clinical cases in the Psychiatry Residence from Hospital das Clínicas, as a teacher in the UFMG School of Medicine in Belo Horizonte, as well as other experiences in different hospitals, clinics and in private practice, in thirty years of intense activity and daily work. By writing this article, the author proposes the use of semiological investigation method, named as phenomenological-dynamic method, that results in a theoretical constructo, in which premorbid personality is an important component, and that enables an accurate, precise and detailed diagnostic hypothesis to be made in clinical practice.In order to illustrate the practical utility of the mentioned method, four clinical cases are presented in this piece of work, which the author uses to establish the concept of primary and secondary "morbus", characterological "filter" and psychopathological markers. Furthermore, the writer mentions other theoretical concepts developed in his previous articles, such psychoid states.
\end{abstract}

Keywords: Phenomenology; Pre-morbid personality; Personality Disorder; Psychopathology markers; Atypical psychoses.

\section{Introdução}

Os primeiros 'constructos' teóricos elaborados pelo autor surgiram na década de noventa e foram aperfeiçoados e aprimorados até culminar em um modelo teórico conceitual que, espera-se, poderá contribuir para aumentar a precisão do diagnóstico em psiquiatria e, além disso, induzir maior rigor e especificidade nas prescrições, intensificando, assim, a eficácia terapêutica do tratamento farmacológico e definindo a natureza da abordagem psicoterápica de cada caso.

O estudo contemporâneo da psiquiatria se ressente notavelmente das valiosas contribuições teóricas dos autores clássicos na área de psicopatologia e semiologia psiquiátrica, constituindo-se o cenário atual da formação 
profissional em algo desalentador, com carência de transmissão do conhecimento de psicopatologia clássica, havendo ênfase desmedida e exclusiva para projetos de pesquisa em biologia molecular ou estudos epidemiológicos calcados no método criteriológico rigidamente atrelado aos DSM (American Psychiatric Association, 1989; 1995) e dirigidos aos psiquiatras iniciantes.

A psiquiatria atual parece ter esquecido da importância essencial do conhecimento em psicopatologia, esse verdadeiro alfabeto semiológico cujo pleno domínio é necessário para a formulação de raciocínios clínicos razoáveis e o estabelecimento de hipóteses diagnósticas bem fundamentadas e confiáveis.

O advento dos DSM (American Psychiatric Association, 1989; 1995), manuais fundados em estudos epidemiológicos e estatísticos, representou, de fato, a aquisição de valiosos instrumentos de classificação das doenças mentais com vistas a tornar o diagnóstico psiquiátrico mais preciso, específico e confiável. As chamadas entrevistas estruturadas e semi-estruturadas, além de questionários específicos para cada transtorno presente no DSM-IV(American Psychiatric Association, 1995), revestem-se de papel cada vez mais importante para o diagnóstico e sua utilização, nos dias de hoje, constitui-se em prérequisito indispensável para que um artigo seja aceito para publicação em periódicos da área.

Entretanto, à medida que a precisão e a confiabilidade do diagnóstico criteriológico tornam-se cada vez mais apuradas, constatamos uma gradual opacificação e embotamento da sensibilidade do médico psiquiatra para perceber os seus pacientes em sua inteireza e totalidade humanas. Desse modo, cada vez tem menos importância a pesquisa e reconhecimento de seu temperamento, conformação pré-mórbida de personalidade, visão de mundo, hábitos, gostos, preferências e singularidades estritamente pessoais inseridas em um determinado padrão histórico-biográfico-existencial e cultural, ou seja, aquele extenso e fecundo microcosmo humano que nunca poderá prescindir do caráter unívoco de pessoalidade presente em cada um de nós. Se for verdade que há algumas décadas, sob o domínio e influência da teoria psicanalítica, privilegiava-se quase tão somente a dimensão histórico-biográfico-existencial em detrimento da abordagem empírico-estatística, pedra angular de qualquer ciência, o inverso também não deixa de ser verdadeiro nos dias de hoje, época na qual assistimos a uma massificação criteriológica do diagnóstico psiquiátrico, com uma consequente desumanização e empobrecimento da captação empática, pelo médico, da singularidade das vivências e da expressão simbólica de seus pacientes. 
Ademais, no que se refere especialmente ao diagnóstico criteriológico das psicoses, de maneira geral, constata-se uma enumeração de sintomas psicopatológicos demasiadamente concisos e, mesmo, simplista, considerandose a grande complexidade e o extremo polimorfismo clínico dessas vivências anômalas tão intrigantes. Com efeito, consideramos que termos psicopatológicos sumariamente abrangentes tais como, por exemplo, "delírios", "alucinações" e "incoerência ou afrouxamento acentuado das associações", presentes nos DSM (American Psychiatric Association, 1989; 1995), que se revelam insuficientes e por demais genéricos para caracterizar vivências psicóticas mais complexas e que sejam marcadas por algum polimorfismo clínico.

Outro grande problema, que surgiu ao se tentar sistematizar a complexidade do diagnóstico em psiquiatria, diz respeito à avaliação multiaxial presente nos DSM (American Psychiatric Association, 1989; 1995), resultando em diagnósticos fragmentados, compartimentados e estaticamente dissociados, além de artificialmente construídos e distantes das realidades clínicas que se apresentam na "vida real", além de se multiplicarem exponencialmente as chamadas e discutíveis comorbidades. No diagnóstico final, as categorias pertencentes aos determinados eixos não interagem, deixando de produzir, como seria de se esperar, amálgamas e fórmulas nosológicas sinteticamente compreensíveis e intrinsecamente lógicas, mas, ao contrário, descrevem uma sucessão escolástica de condições e situações clínicas desconectadas entre si para a desejável convergência e consequente formulação da hipótese diagnóstica mais plausível e completa.

Desse modo, faz-se necessária uma ampliação do horizonte teórico conceitual disponível com vistas ao esclarecimento e à elucidação de alguns sintomas psicopatológicos necessários para a sólida fundamentação do diagnóstico em psiquiatria, além de facilitar sobremaneira a visualização mais nítida e segura do diagnóstico diferencial, especialmente nos casos clínicos mais complexos. É nosso propósito que o presente texto, desprovido de qualquer pretensão estatística que objetivasse a validação de parâmetros em determinada amostragem, corresponda a uma diretriz padronizada de investigação estritamente semiológica que possa ser replicada em qualquer contexto clínico que se apresente ao examinador em busca de um diagnóstico correto, preciso e detalhado. A verdadeira validação dessa tarefa foi construída ao longo dos anos, durante os quais um padrão de raciocínio clínico foi utilizado, com êxito, na supervisão de muitas centenas de casos na residência de psiquiatria do Hospital das Clínicas da UFMG, sendo largamente aprovado e adotado por inúmeras gerações de residentes que por lá passaram e o continuam usando devido à sua praticidade e eficácia. Assim, se faltam números exatos de amostragem e tabelas de análise estatística, sobram testemunhos de 
reconhecimento da utilidade de aplicação proveitosa do modelo de 'constructo' teórico aqui proposto.

Iniciaremos a presente tarefa com a conceituação do método fenomenológico-dinâmico, concepção teórica que não é propriamente inédita, desde que foi publicada já há alguns anos em outros artigos (Souza, 1990, 1998a, 1998b, 1999, 2000a, 2000b, 2000c), mas cuja revisão e revalidação se tornam necessárias em virtude de se constituir na verdadeira espinha dorsal do modelo de raciocínio clínico que será aqui proposto. Em seguida, discorreremos sobre a importância da caracterização da personalidade pré-mórbida na engrenagem lógica do modelo teórico-prático construído - em paralelo com o conceito de transtorno e (ou) traços de personalidade - culminando com a apresentação de quatro casos clínicos e sua simultânea discussão.

\section{I-O método fenomenológico-dinâmico}

No decorrer de duas décadas de supervisão de casos clínicos no ambulatório, nasceu a necessidade de estabelecer um método bem definido e que fosse capaz, não somente de levar a cabo uma investigação semiológica detalhada, profunda e precisa, mas, também, de elaborar um 'constructo' teórico de cada caso com a finalidade de eleger as condutas terapêuticas mais adequadas para cada um deles.

Com o decorrer do tempo, foi sendo desenvolvido um método investigativo semiológico rotineiro que pôde contemplar o alinhamento de dados provenientes da captação empática das vivências do paciente, procedimento estritamente fenomenológico, ao lado de outros dados oriundos de uma anamnese capaz de delinear a personalidade pré-mórbida, trajetória biográfico-existencial, as mudanças ocorridas após o adoecer psíquico e identificar variáveis importantes, tais como estressores psicossociais e elementos psicodinâmicos, que eventualmente fossem decisivos para o desencadeamento, manutenção ou agravamento do quadro clínico.

A denominação de tal método com o termo fenomenológico-dinâmico (Souza, 1990, 1998a, 1998b, 1999, 2000a, 2000b, 2000c) resultou do objetivo central da investigação semiológica: procurar visualizar o extremo dinamismo e o contínuo movimento que permeiam as modificações fisiopatológicas ao lado daquelas fenomenológicas e que ocorrem a cada momento. Só assim abandonaremos a visão estática, compartimentada e imobilizante que sempre 
anuvia e limita o senso clínico, desviando-nos da diversidade e das múltiplas possibilidades de visualizar algo psicopatologicamente novo.

Com a utilização desse método, descortinou-se a perspectiva ampla de se formular, rotineiramente, esquemas teóricos de diagnóstico em psiquiatria com a vantagem de diminuir razoavelmente a margem de erro diagnóstico e, consequentemente, a ineficácia ou baixa resolutividade dos tratamentos instituídos. Após algum tempo, evidenciou-se sua grande utilidade como instrumento de elucidação de mecanismos fisiopatológicos do adoecer psíquico e, como corolário imediato, o expressivo aumento da precisão do diagnóstico psiquiátrico e da resolutividade daqueles casos clínicos especialmente complexos e desafiadores.

$\mathrm{O}$ método fenomenológico-dinâmico, à semelhança de uma lente de aumento bastante específica, propiciou que certas etapas do adoecer psíquico, antes obscuras, fossem colocadas à mostra em toda sua inteligibilidade intrínseca, permitindo uma visão perfeitamente encadeada e lógica da morfologia clínica como um todo, notadamente de quadros atípicos ou indiferenciados. Além disso, mostrou-se ferramenta útil em relação ao diagnóstico diferencial em psiquiatria, dirimindo dúvidas e norteando diretrizes terapêuticas mais específicas e resolutivas. Através de seu constante emprego para a dissecação psicopatológica e elucidação dos quadros psiquiátricos em geral, foi-se estabelecendo a importância do achado de certos elementos semiológicos para a caracterização precisa de determinados transtornos psiquiátricos. Desse modo, nasceu o conceito de marcadores psicopatológicos, que podem ser definidos como determinadas alterações das funções psíquicas ou dados específicos da anamnese psiquiátrica e que podem caracterizar um quadro psiquiátrico com precisão e segurança em termos diagnósticos. Tal conceito, sem dúvida, inspirou-se no de 'marcador biológico' que consiste em qualquer estrutura, composto ou atributos biológicos que evidenciam a presença de um transtorno específico ou de uma vulnerabilidade ao mesmo. Certamente, os marcadores psicopatológicos não possuem a mesma precisão dos biológicos, mas podem auxiliar em muito a caracterização de um determinado quadro clínico e seu diagnóstico com toda sua complexidade. Podem servir como exemplos de marcadores psicopatológicos: traços específicos de personalidade pré-mórbida, temperamento, alterações peculiares das funções psíquicas, vulnerabilidade pessoal e familiar, variáveis psicodinâmicas e ocorrência de determinados estressores psicossociais. Os exemplos clínicos acompanhados de sua discussão, mais à frente, servirão para ilustrar o que vem sendo estabelecido até aqui.

De modo similar, como veremos adiante, a utilização de outros conceitos, tais como 'morbus' primário, 'morbus' secundário e 'filtro' caracterológico (Souza, 
1998a, 1998b, 1999, 2000a, 2000b, 2000c), ao lado dos chamados marcadores psicopatológicos, serão de imensa valia para a concatenação e interação de diversos elementos semiológicos que, dinamicamente, confluirão para configurar a morfologia clínica final.

De imediato, alguns esquemas teóricos evidenciaram uma distinção importante entre dois grupamentos praticamente antagônicos de sintomas psicopatológicos. No primeiro grupo, evidenciou-se que a morfologia clínica final era o resultado de uma patoplastia, ou seja, de uma espécie de hipertrofia da psicopatologia prévia, enquanto no segundo grupo concluiu-se que sintomas psicóticos atípicos, em outra parte denominados pelo termo psicoide (Souza, 1998a, 1998b, 1999, 2000a, 2000b, 2000c), correspondiam a algo fenomenologicamente novo e inusitado.

A seguir, faz-se necessário discorrer mais extensamente sobre o primeiro passo do método fenomenológico-dinâmico, que é a caracterização da personalidade pré-mórbida do paciente a ser estudado, assunto cuja importância nunca será demais de ser sublinhada.

\section{I.a-A caracterização da personalidade pré-mórbida}

Já podem ser considerados clássicos os estudos de Cloninger (Cloninger, Przybeck \& Svrakic, 1991; Cloninger, Svrakic \& Przybeck, 1993; Svrakic, Whitehead, Przybeck \& Cloninger, 1993) sobre os transtornos de personalidade, assim como as quatro dimensões de temperamento por ele desenvolvidas através do Questionário de Personalidade Tridimensional (TPQ) e do Inventário do Temperamento e Caráter (TCI). Esse autor vem realizando, há décadas, pesquisas utilizando dados genéticos, neurobiológicos e neurofarmacológicos com o objetivo de identificar vulnerabilidades individuais e/ou) familiares para certos transtornos psiquiátricos, além de tentar distinguir predisposições genético-comportamentais daquelas modalidades de conduta adquiridas e modificadas pelo ambiente. Sem dúvida, trata-se de trabalho extenso, árduo e rigoroso, mas cuja discussão mais pormenorizada ultrapassaria as dimensões e objetivos deste artigo, tendo o leitor interessado no tema quantidade considerável de referências bibliográficas em inúmeros endereços eletrônicos.

Em suma, para cumprir os objetivos deste texto, faz-se necessário resumir as quatro dimensões de temperamento desenvolvidas e conceituadas por Cloninger (Cloninger, Svrakic \& Przybeck, 1993): 
- $\quad$ Prevenção contra danos

- $\quad$ Procura por novidades

- $\quad$ Dependência por recompensa (aprovação)

- $\quad$ Persistência

Vale dizer que essas dimensões conceituais de temperamento contribuíram para a atual classificação de transtornos de personalidade presentes no DSM-IV (1) e que são distribuídas em três grupos. Recapitulando, o Grupo 'A', também denominado "Excêntrico ou Bizarro" abriga os Transtornos Esquizoide, Esquizotípico e Paranoide.

O Grupo 'B', também chamado "Errático ou Dramático”, contém os Transtornos Narcisista, Anti-Social, Histriônico e "Borderline".

O Grupo 'C', intitulado “Receoso ou Temeroso”, alinha os Transtornos Anancástico (Obsessivo), Ansioso (Evitativo) e Dependente.

Como se pode visualizar, panoramicamente, o Grupo ' $\mathrm{C}$ ' se caracteriza pela predominância da dimensão de prevenção contra danos (medo, apreensão e temor), enquanto no Grupo ' $\mathrm{B}^{\prime}$ se ressalta a dimensão de procura ou busca por novidades (prazer, novas sensações). Por outro lado, no Grupo 'A' se destacam a frieza ou indiferença afetiva à aprovação (esquizoides e esquizotípicos) contrastando com a suscetibilidade afetiva e desconfiança exageradas dos pacientes paranoides. Mais especificamente, à guisa de exemplos, um paciente com Transtorno "Borderline" de Personalidade possui procura por novidades alta, prevenção contra danos baixa, dependência à recompensa alta; no Transtorno Anti-Social há procura por novidades alta, prevenção contra danos e dependência à recompensa muito baixas, enquanto no obsessivo a prevenção contra danos é muito alta e a procura por novidades baixa (Cloninger, Svrakic \& Przybeck, 1993).

Por outro lado, deve-se sempre ter em mente a concepção de que os transtornos de personalidade são amplificações dos traços normais da personalidade (Paris, 1996), o que é sustentado pela evidência de um continuum entre traços e alterações (Livesley et al, 1992). Em outras palavras, para fins práticos, cada pessoa, em princípio, possui um padrão de personalidade que dificilmente não é representada por uma dessas tendências fundamentais, ou seja, pela predominância da procura por novidades e do prazer, do medo e da excessiva cautela, da necessidade de aprovação e da determinação e obstinação. 
Dessa maneira, tendo-se o cuidado de não simplificar demasiadamente e sublinhando-se que são disposições temperamentais de base, podemos estabelecer padrões cognitivo-afetivos e de predisposição comportamental, ambos relativamente uniformes na população geral:

- Indivíduos beligerantes, hostis, irritáveis, estranhos, exageradamente desconfiados ou frios, solitários e distantes.

- Impulsivos, destemidos, aventureiros, pouco compassivos, insensíveis, despreocupados e irresponsáveis ou excessivamente apegados, instáveis, dramáticos e teatrais.

- Receosos, pessimistas, exageradamente escrupulosos, detalhistas, perfeccionistas, dependentes, preocupados com a avaliação de terceiros e com tendência acentuada à culpa.

- Determinados, obstinados e teimosos ou, tímidos, facilmente desencorajados e influenciáveis.

Somente aqueles profissionais com bastante experiência clínica e muitos anos de prática profissional poderão reconhecer, com nitidez, que a totalidade de seus pacientes - respeitando-se as singularidades pessoais, trajetórias biográfico-existenciais e contextos culturais unívocos - possui traços de personalidade tais como os acima descritos, podendo ser mistos, esparsos, diluídos ou concentrados, mas, de qualquer maneira, sobressaindo-se como determinada tendência fundamental.

Na prática clínica, são bastante úteis outros conceitos correlatos, tais como caráter, personalidade e temperamento, visto que são peças importantes na engrenagem do raciocínio clínico que resulta na hipótese diagnóstica.

O caráter pode ser definido como o resultado da interação entre temperamento, ambiente familiar e experiências de vida individuais (Svrakic et al., 1993).

A personalidade é o resultado da combinação entre o temperamento básico e o caráter, que se forma pela experiência (Cloninger et al., 1993).

O temperamento pode ser conceituado como estado de ânimo básico ou atitude afetiva geral que caracteriza a individualidade e seus padrões de reação (Kretschmer, 1954).

Akiskal (Akiskal, 1992; Akiskal \& Mallya, 1987) se inspirou nos temperamentos de Hipócrates e conceituou os temperamentos hipertímico, depressivo, ciclotímico e irritável em seus estudos sobre o espectro bipolar. De 
acordo com esses estudos, postulou que: 1- um episódio maníaco incidindo em pessoa com temperamento depressivo resulta em estados mistos psicóticos. 2um episódio depressivo maior incidindo em pessoa com temperamento ciclotímico resulta em quadro clínico caracterizado por humor depressivo, hiperfagia, fadiga e hipersonia. 3- um episódio de depressão maior acometendo pessoa com temperamento hipertímico resulta em quadro disfórico, acompanhado de irascibilidade e agitação (Akiskal, 1992; Akiskal \& Mallya, 1987; Marneros, 2001).

Para fins práticos de raciocínio clínico, pode-se considerar que a personalidade é o resultado final da interação dinâmica entre o patrimônio caracterológico, com toda sua gama de predisposições temperamentais,padrões potenciais de reação e vulnerabilidades, essencialmente transmitidos pela herança genética, com as circunstâncias ambientais. Caberia, desse modo, a fórmula $\mathrm{P}=\mathrm{HxA}$ como tentativa de representar a personalidade $(\mathrm{P})$ como produto da interação entre herança $(\mathrm{H})$ e ambiente $(\mathrm{A})$.

De qualquer maneira, é necessário sublinhar que todos os conceitos enumerados até agora serão utilizados como verdadeiras peças de encaixe na construção do raciocínio clínico completo, cujo esquema gráfico de diagnóstico (figura 1) corresponde ao 'constructo' teórico padrão de análise de casos clínicos e que pode ser visualizado a seguir (Figura 1 - Esquema gráfico padrão de diagnóstico):

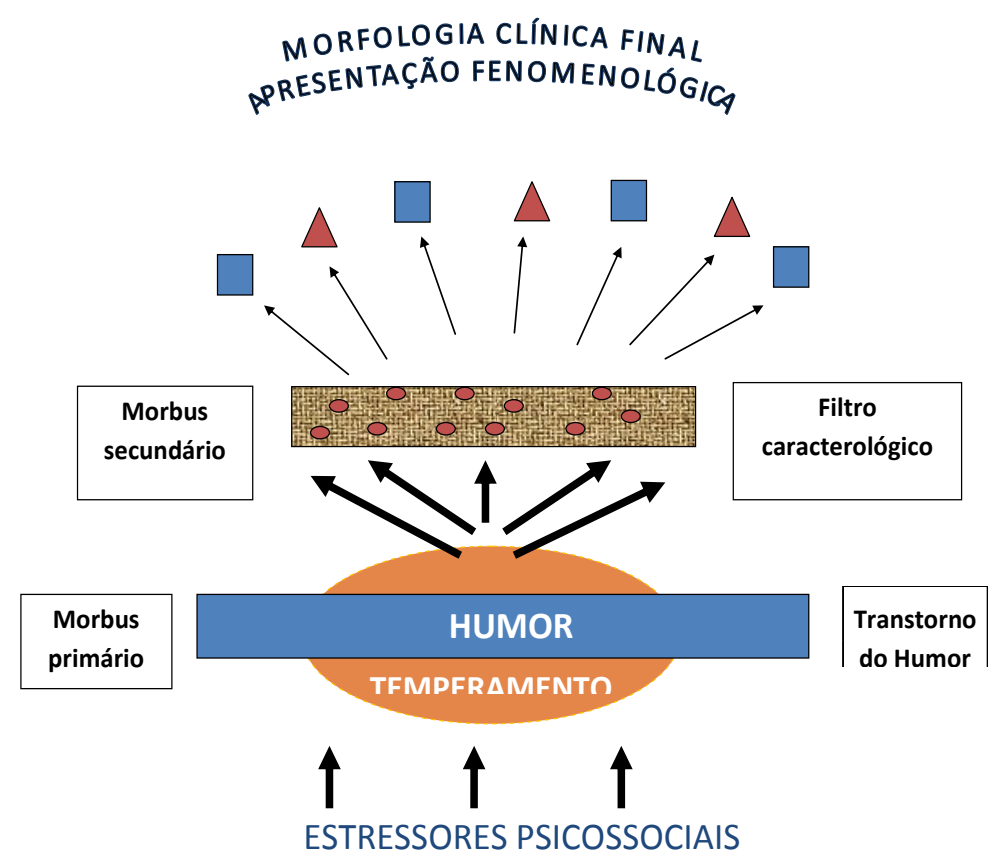


De acordo com a figura acima, pode-se visualizar como um determinado transtorno do humor ("morbus" primário) atuando em certo padrão de 'filtro' caracterológico, desencadeará mudanças fisiopatológicas decisivas ("morbus" secundário) e que produzirá a morfologia clínica final, ou seja, a fenomenologia predominante do quadro clínico em estudo. Além disso, estão presentes outras variáveis decisivas, tais como a presença e natureza de estressores psicossociais e modalidade do temperamento.

\section{II- Raciocínio clínico em psiquiatria: exemplos de casos clínicos}

Através da breve apresentação e discussão de casos clínicos, pretende-se ilustrar a sequência pormenorizada do raciocínio clínico empregado para estabelecer-se o diagnóstico final em cada um deles.

\section{Caso clínico 1:}

Trata-se do Sr. A., 54 anos, casado, encarregado geral em uma fábrica. Ele trabalha em uma empresa familiar desde muito jovem, mas há cerca de três meses vem sentindo mudanças significativas em seu comportamento e bastante desconforto no trato com outras pessoas. Manifesta medo irracional e acentuado para conversar com terceiros, principalmente se são superiores hierárquicos no ambiente de trabalho. Nesses momentos, sente-se invariavelmente embaraçado, começa a gaguejar, apresenta sudorese e taquicardia. Em certas ocasiões, a hiperatividade autonômica e aumento da frequência respiratória são compatíveis com ataques de pânico. O Sr. A. é oriundo de família humilde, sempre se considerou pessoa muito tímida, desde a infância, e nunca ambicionou melhorar de vida profissionalmente. É homem de rotina rígida e tediosa, moralmente muito escrupuloso e de hábitos simples e frugais. A esposa também trabalha na fábrica há muitos anos, tem dois filhos e união conjugal sólida e estável.

Apesar de sempre ter sido pessoa tímida e arredia, sente que agora está muito pior. Chega a esconder-se dos superiores e dos colegas de trabalho, vive permanentemente amedrontado e em sobressalto, além de apresentar insônia terminal, despertando às três horas da madrugada e não mais dormindo, com indisposição e absoluta falta de vontade de se levantar pela manhã, melhorando com o passar do dia, tristeza inexplicável e labilidade afetiva, emocionando-se por qualquer motivo e chegando facilmente às lágrimas. Emagreceu nesse período, tendo perdido aproximadamente três quilos.Vê-se abatido e trêmulo e se sente "encurralado", segundo suas próprias palavras. 


\section{Hipótese Diagnóstica:}

Transtorno de Ansiedade Social agudo desencadeado por Episódio Depressivo em personalidade com importantes traços obsessivos e evitativos (Grupo 'C') (American Psychiatric Association, 1995).

O tratamento consistiu na prescrição de cloridrato de paroxetina (20mg/dia) associado a clonazepam ( $2 \mathrm{mg} /$ dia). O Sr. A. obteve alívio imediato dos sintomas ansiosos e evitativos mais agudos, ocorrendo elevação gradual do humor depressivo e remissão completa dos sintomas ansiosos e depressivos ao longo de noventa dias. Posteriormente, o controle ambulatorial quinzenal com a manutenção de $20 \mathrm{mg} /$ dia de paroxetina e $1 \mathrm{mg} /$ dia de clonazepam, aliado ao emprego de estratégias cognitivo-comportamentais (TCC) específicas para o caso, garantiu a estabilidade do humor e a normalização dos contatos sociais, recebendo alta após um ano de acompanhamento.

\section{Discussão do caso:}

A análise do comportamento e estilo geral de vida do Sr. A. antes de seu adoecimento, há cerca de três meses, revela temperamento depressivo e personalidade pré-mórbida com marcantes traços obsessivos e evitativos sociais (Grupo 'C'/Receoso ou Temeroso) (American Psychiatric Association, 1995). Sem dúvida, a sua placidez, seu acomodamento e monotonia existenciais, além de seu congelamento profissional, retratam um homem constantemente preocupado e apreensivo em cumprir à risca todos os seus deveres e obrigações, evidenciando um padrão de prevenção contra danos (Cloninger, Svrakic \& Przybeck, 1993) bastante elevado. Muito provavelmente, desde cedo foi acometido por uma distimia de evolução crônica e caráter flutuante com períodos de exacerbação e outros de atenuação dos sintomas depressivos, mas de intensidade leve, a ponto de se confundir ou, mesmo, sobrepor-se ao temperamento depressivo de base. A eclosão de um episódio depressivo maior, configurando uma depressão dupla, de severa intensidade, ("morbus" primário), amplificou dramaticamente os traços obsessivos e evitativos sociais de sua personalidade pré-mórbida, desencadeando modificações fisiopatológicas significativas ("morbus" secundário), que culminaram no desencadeamento de um quadro de Transtorno de Ansiedade Social agudo.

Podem ser considerados marcadores psicopatológicos, neste caso, os traços da personalidade pré-mórbida do grupo ' $C$ ', ou seja, predisposições caracterológicas obsessivas e evitativas sociais e que foram determinantes para a gênese da morfologia clínica final (T. de Ansiedade Social agudo). A visão esquemática da sequência dos fenômenos psicopatológicos pode ser visualizada, a seguir, de acordo com a figura 2: 


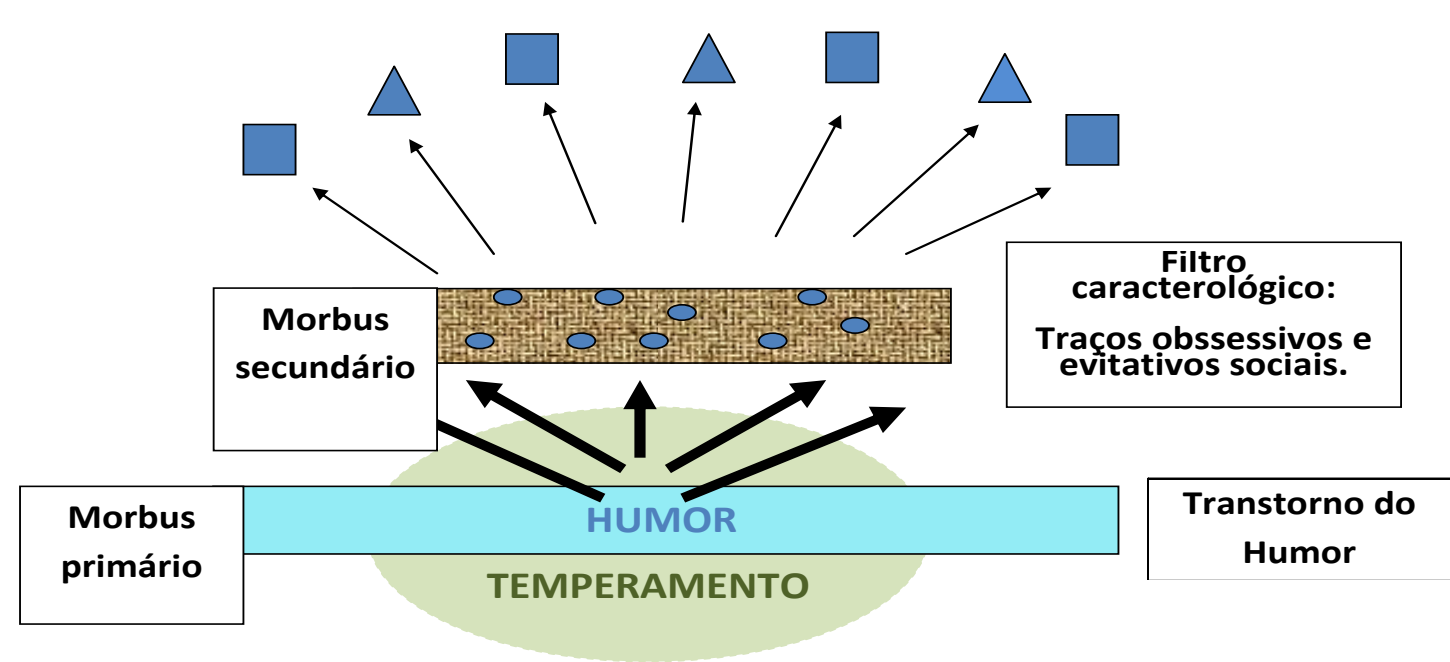

Caso clínico 2:

O Sr. X, 52 anos, solteiro, empresário, iniciou tratamento comigo há quatro anos. Relatou, na primeira consulta, longo histórico de tratamento psiquiátrico desde os vinte e cinco anos de idade, segundo ele, em virtude de "depressão" (sic). Havia se consultado com um bom número de psiquiatras e, além de inúmeros tratamentos farmacológicos com antidepressivos e moduladores do humor, todos ineficazes, também já tinha se submetido a eletroconvulsoterapia (ECT) e, mais recentemente, estimulação magnética transcraniana (EMtr), igualmente sem nenhum resultado terapêutico.

O Sr. X, no início do tratamento, apresentou-se como empresário empreendedor, criativo e dinâmico, que havia fundado uma concessionária de automóveis, seguida por uma empresa de loteamento de terrenos. Segundo ele, ambos os negócios, apesar de começarem muito bem, após algum tempo faliram, restando-lhe apenas dívidas. Era sustentado integralmente pelo pai, um advogado de renome, homem octogenário de posses, firme e severo. O paciente era bem apessoado, procurava transmitir bom humor e simpatia através de conversação envolvente e agradável. Entretanto, logo se revelou manipulador, egocêntrico e bastante imaturo, demonstrando grande irritação quando frustrado ou contrariado, explodindo em rompantes exagerados de cólera e indignação. Manifestava abundantes queixas somáticas, notadamente dores localizadas na cabeça, tórax e membros inferiores. Em muitas consultas 
massageava freneticamente essas regiões e afetava muita dramaticidade nos gestos e voz. Os sintomas somatoformes se multiplicavam vertiginosamente a cada consulta e desapareciam completamente na sessão seguinte, sendo substituídos por novas e inusitadas queixas, quase todas vagas e inespecíficas. Havia, periodicamente, consumo excessivo de álcool, benzodiazepínicos e analgésicos opioides e procurava controlar as prescrições médicas, questionando sua validade, enfim, tumultuava bastante o tratamento. A conduta terapêutica consistia em ensaios terapêuticos com doses baixas de antidepressivos (mirtazapina) associados a moduladores do humor, especialmente a lamotrigina, além de sessões semanais de psicoterapia.

Um ano após iniciar tratamento, tornou-se sócio da namorada em um novo negócio. No começo, mostrou-se bastante animado e empreendedor. Após algum tempo, foi ficando loquaz, taquipsíquico e cada vez mais exaltado. Começou a exagerar nas compras para reposição de estoque da loja. Não aceitava ponderações da sócia, tornou-se autoritário, agressivo e passou a acalentar sentimentos e fantasias de grandiosidade. As crises de cólera se sucederam, assim como se agravaram bastante os abusos de álcool, benzodiazepínicos e opioides. Não respondeu a 700mg/dia de quetiapina, o que acarretou indicação de internação hospitalar. Os problemas não cessaram nesse ponto, desde que havia cometido várias irregularidades financeiras na empresa, o que exigiu intervenção de seu pai, contratando advogados e assumindo todas as dívidas. Descobri, então, tardiamente, que esta era mais uma aventura comercial nos mesmos moldes das anteriores, nas quais havia fracassado e falido, naufragando em crises com características bastante semelhantes à atual, incluindo o salvamento e resgate feito pelo pai.

Após esse acontecimento, passou a viver praticamente recluso, controlado e supervisionado rigidamente pelo pai e submetendo-se a tratamento psicoterápico com um psicólogo da clínica onde fora internado. Passou a fazer controle ambulatorial comigo apenas de quarenta em quarenta dias para revisão clínica e medicamentosa. Entretanto, como teimava em aumentar as doses dos medicamentos prescritos de acordo com suas próprias deliberações, o tratamento foi encerrado aproximadamente um ano depois.

\section{Hipótese Diagnóstica:}

Fase maníaca em paciente com Transtorno de Personalidade do Grupo 'B' (Dramático ou Errático com traços histriônicos, 'borderline' e anti-sociais) (American Psychiatric Association, 1995), culminando em distúrbios comportamentais graves, persistentes e refratários. 


\section{Discussão do caso:}

O Sr. X, desde jovem, sempre apresentou comportamento aventureiro e irresponsável (procura por novidades alta, prevenção contra danos baixa e dependência à aprovação baixa) (Cloninger, Avrakic \& Przybeck, 1993), culminando em falências de empresas que dirigiu e prejuízo financeiro para terceiros. Também era dotado de temperamento hipertímico, o que contribuía para colorir seus projetos e fantasias com tons de grandiosidade, otimismo excessivo e, até, de irrealidade. Desse modo, convencia-se da exequibilidade de algum planejamento empresarial grandioso, mesmo diante de evidências de realidade desfavoráveis, terminando por persuadir outras pessoas que não o conhecessem através de mentiras e argumentos inverossímeis. Nesse ponto, as mentiras - não somente no âmbito empresarial, mas também na esfera pessoal repetiam-se com tamanha frequência, banalidade e naturalidade em seu cotidiano que adquiriam o caráter de verdadeira e maciça mitomania. Além disso, em certos períodos, possivelmente coincidindo com ciclagens ultrarrápidas de humor, consumia grandes quantidades de álcool, benzodiazepínicos e analgésicos opioides. O comportamento manipulador e envolvente, as estratégias de sedução aliadas a inúmeras queixas somáticas, considerando-se, ainda, a extrema imaturidade que acarretava inteira dependência do pai, situam sua personalidade no Grupo 'B' (American Psychiatric Association, 1995), ou seja, com traços histriônicos, 'borderline' e anti-sociais, o que, por si só, já traduz gravidade significativa e prognóstico sombrio. No entanto, a eclosão de uma fase maníaca (Transtorno do humor/"morbus" primário) amplificou consideravelmente tais padrões de predisposições vivenciais (Transtorno de personalidade/"morbus" secundário), agravando dramaticamente certas peculiaridades não adaptativas de seu comportamento e tornando o quadro clínico absolutamente refratário e intratável. Podem ser considerados marcadores psicopatológicos, neste caso, os já citados traços de personalidade pré-mórbida do Grupo 'B' e a análise longitudinal de sua trajetória biográfica, marcada por oscilações e ciclagens rápidas do humor e distúrbios comportamentais.

A visão esquemática do caso pode ser visualizada na figura 3: 


\section{Exemplos clínicos \\ Caso clínico 2 (Figura 3)}

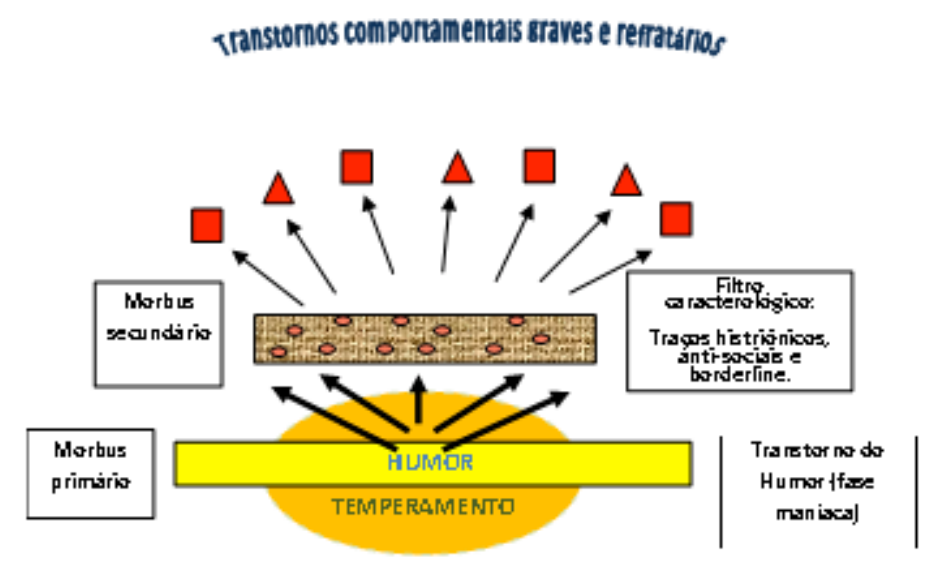

Caso clínico 3:

A Sra. R., 37 anos, casada, duas filhas, comerciante, foi à primeira consulta psiquiátrica devido a encaminhamento da cardiologia após permanecer hospitalizada durante quatro dias para a realização de exames e controle medicamentoso para hipertensão arterial sistêmica que se instalara de maneira súbita e inesperada. Uma semana antes dessa internação, ao consultarse a propósito de um torcicolo, descobrira, para sua surpresa, que os seus níveis pressóricos arteriais estavam elevados, com muitas oscilações e sem melhora com o tratamento anti-hipertensivo ambulatorial. Sua saúde geral sempre fora muito boa, não havia antecedentes mórbidos e mostrava-se muito assustada e apreensiva com o problema. Desenvolvera, desde então, o hábito de medir a pressão arterial várias vezes ao dia e, a cada mensuração, preocupava-se seriamente em sofrer alguma complicação cardiovascular, tal como infarto do miocárdio ou AVC. Nesses momentos, sentia-se sufocada, com a respiração curta, palpitações, sudorese, tonteiras e mal estar generalizado. Nessas condições, quando verificava a PA e constatava que estava elevada, ficava ainda mais ansiosa e apreensiva, tomava os medicamentos anti-hipertensivos e aguardava certo período de tempo para nova verificação. Pensava que poderia morrer a qualquer momento e deixar as filhas desamparadas, ainda mais que, em sua família, havia vários casos de doenças cardiovasculares em parentes de primeiro e segundo graus. Quase não dormia, alimentava-se muito pouco e chegou a emagrecer cerca de 3 quilos em duas semanas. Relatava, também, angústia e crises de choro. 
A anamnese revelou que tinha outra irmã de 35 anos, os pais haviam se separado quando tinha três anos de idade após a mãe abandonar a casa sem nenhum aviso, casou-se aos dezenove anos e teve a primeira filha aos vinte e cinco. A segunda filha tinha nascido há um ano e meio e, devido ao diagnóstico de bronquiolite, constatada no décimo dia de vida, havia permanecido durante quinze dias no CTI com poucas chances de sobrevivência. No final, a menina conseguiu a cura, mas tamanha tensão acabou por provocar preocupação exagerada em relação à filha, tendo desenvolvido rituais de higiene e prevenção de doenças excessivos e inadequados. Alguns meses depois do acontecido, começou a vivenciar "flashbacks" relacionados ao período de hospitalização da filha, numa espécie de transtorno de estresse pós-traumático brando e protraído. Há cerca de quarenta dias descobriu que o marido estava assediando uma funcionária da loja. Ficou chocada e profundamente decepcionada com ele.

A Sra. R. é pessoa discreta, contida e formal. Desde muito nova, educada pela avó paterna rígida a partir do abandono da mãe, sempre foi muito exigente consigo mesma, organizada, perfeccionista, detalhista e obstinada. Tem hábitos austeros e disciplinados, é muito pontual e se preocupa em demasia com dívidas e cumprimento de compromissos assumidos. É dedicada à família e ao trabalho. Na entrevista, revela ter muitas dificuldades para exprimir raiva, preferindo, na maior parte das vezes, engolir o descontentamento e dissimular suas mágoas e desgostos.

\section{Hipótese Diagnóstica:}

Transtorno misto de ansiedade e depressão entremeado com ataques de pânico acompanhados de alterações psicofisiológicas agudas (crises ou "picos" hipertensivos) em personalidade pré-mórbida com traços obsessivos (prevenção contra danos elevada/Grupo 'C', Temeroso ou Receoso) (American Psychiatric Association, 1995; Cloninger, Svrakic \& Przybeck, 1993) e vulnerabilidade familiar aumentada para doenças cardiovasculares.

O tratamento consistiu na prescrição do anti-depressivo mirtazapina na dose de 30mg/dia, considerando-se sua ação sedativa e ansiolítica, associado ao benzodiazepínico de curta ação alprazolam, na dose de 1,5mg/dia. Além do tratamento farmacológico, iniciou-se uma abordagem psicoterápica de teor psicodinâmico visando um procedimento de interpretação e clarificação de seus sintomas em um ambiente de acolhimento e facilitação da expressão de seus sentimentos e emoções. Passei a atendê-la quinzenalmente. A melhora dos sintomas agudos ocorreu rapidamente e, cerca de dois meses depois, houve remissão completa dos sintomas ansiosos, depressivos e das crises hipertensivas, além da normalização de sua rotina de vida. 


\section{Discussão do caso:}

A Sra. R., com nítida constituição caracterológica obsessiva e com história familiar sugerindo vulnerabilidade cardiovascular, foi submetida à exposição de estressores psicossociais importantes no período de um ano e meio (doença da filha recém-nascida e grave decepção conjugal). O primeiro período de exposição a estressores (doença da filha) ocasionou transtorno de estresse pós-traumático (TEPT) brando e protraído, fragilizando da homeostase de seu organismo. Não resistiu à segunda exposição a estressores (decepção conjugal), ocasião na qual ocorreu a ruptura completa daquele equilíbrio e provocando o desencadeamento de todos os sintomas agudos.

O episódio depressivo, operando no 'filtro' ou 'prisma' caracterológico obsessivo-ansioso, aliado à vulnerabilidade cardiovascular ("morbus" primário), desencadeou novas alterações fisiopatológicas ("morbus" secundário) que resultaram em ataques de pânico e crises (picos) hipertensivos arteriais. Estas, por seu turno, passaram a atuar como estressores secundários em um mecanismo de retroalimentação ansiogênica, considerando-se a extrema apreensão e insegurança que ocasionavam. Pode-se considerar, neste caso, os seguintes marcadores psicopatológicos: traços obsessivos de personalidade, vulnerabilidade familiar cardiovascular e exposição a estressores psicossociais importantes.

Ademais, neste caso, é importante comentar algumas observações que registrei ao longo do acompanhamento psicoterapêutico da Sra. R. Em primeiro lugar, chamou minha atenção sua descrição do fato mais marcante de sua infância e que era o abandono que sofreu da mãe quando contava com três anos de idade. Disse que o pai, certa noite, havia levado-a juntamente com a irmã mais nova em uma festa de aniversário de outra criança da vizinhança. Ao voltarem da festinha, constataram que a mãe havia "sumido" de casa, levando todas as suas roupas e pertences. Debalde procuraram-na em todas as residências próximas e, depois de muito perguntarem, já em desespero, receberam a constrangida revelação de um dos vizinhos confessando que ela havia partido com o amante. A paciente revivia essa cena com muito sofrimento, debulhando-se em lágrimas e soluços todas as vezes que, por alguma associação livre de ideias, evocava-a durante as sessões. Afirmava se lembrar desse acontecimento com extraordinária nitidez, em que pese a sua pouca idade à época e o grande período de tempo decorrido. Ela deu-se conta, também, que, a partir desse fato, tornou-se incapaz de fixar qualquer lembrança em sua memória, incluindo-se aí elementos corriqueiros tais como os nomes dos colegas de escola, suas fisionomias e, também, fatos de seu cotidiano doméstico e rotineiro. Esse fenômeno só terminou aos dez anos de idade, época na qual começaram a delinear-se suas "primeiras" lembranças infantis, onde se via 
trabalhando arduamente na casa sob supervisão da avó paterna, cuidando de sua organização e zelando pela irmã mais nova como se fosse sua mãe. Naturalmente, o mecanismo psicológico de defesa do 'eu', no caso representado pela brutal repressão de representações, sentimentos e emoções, terminou por protegê-la de dano psíquico mais sério, deixando apenas grande e incômoda lacuna mnêmica em sua história de vida. Entretanto, à medida que revisitava o passado, a intensa 'anestesia' afetiva em relação à mãe começava a desfazer-se e permitia-se vivenciar sentimentos e emoções mais compatíveis com a situação de abandono, tais como raiva, medo e insegurança. É importante ressaltar, também, a importância de sua contenção emocional para a gênese dos distúrbios psicofisiológicos representados pelas crises hipertensivas. Em uma visão simbólica, pode-se afirmar que a pressão emocional interna, resultante da enorme contenção, materializou-se em hipertensão arterial. Após aproximadamente seis meses de psicoterapia, além da remissão dos sintomas psicofisiológicos, passou a experimentar, naturalmente, algumas mudanças favoráveis em seu modo de se relacionar com a família e com outras pessoas. Houve progressiva atenuação da contenção emocional, relacionando-se de maneira mais genuína e espontânea e diminuindo sobremaneira sua severa auto-exigência.

Desde a infância, sentia-se responsável pela irmã mais nova e, até hoje, ainda a tratava como menina desamparada e carente, desdobrando-se, interferindo e se desgastando com os seus problemas de relacionamento conjugal. Desempenhava o papel de mãe conciliadora e pacificadora, mesmo à custa da resolução de suas próprias dificuldades conjugais. Pouco a pouco, foi conseguindo se desvincular dessa função maternal e passou a concentrar-se mais em seus próprios problemas. Por outro lado, seu pai havia desenvolvido enfermidade neurodegenerativa de evolução clínica desfavorável e ela assumiu cada vez mais os cuidados em relação a ele juntamente com a irmã. De qualquer maneira, à medida que melhorava, os compromissos assumidos já não eram vivenciados de modo tão desgastante e sofrido como antes. Hoje considero, sem nenhuma dúvida, que o principal estressor a que foi exposta em toda a sua vida foi aquele correspondente ao abandono materno. Isso provocou algumas feridas em seu psiquismo que, talvez, nunca se cicatrizem completamente, mas que podem diminuir bastante em relação à extensão dos danos psicológicos encontrados. É mister afirmar que, neste caso, somente uma abordagem terapêutica que privilegiasse a investigação psicodinâmica profunda e viabilizasse a plena expressão afetiva e emocional poderia resultar em resultados terapêuticos eficazes e encorajadores.

O presente caso pode ser graficamente visualizado através da figura 4: 


\section{Caso clínico 3 (fig.4)}

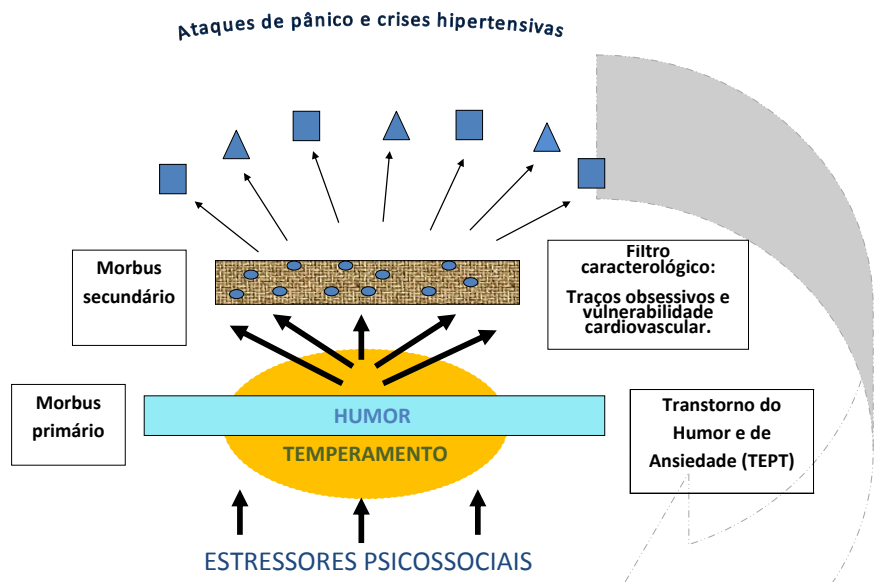

Caso clínico 4:

Trata-se da paciente M., 36 anos, casada, com uma filha de sete anos, profissional da área da saúde de nível superior e que estava internada em um hospital psiquiátrico em setembro de 1992, ocasião na qual comecei a atendê-la por solicitação de seu marido. Tratava-se de uma mulher esguia, gestos delicados, fala pausada e lenta. Estava magra e abatida, mostrando olhar melancólico no semblante carregado e cansado. Mostrou-se cooperativa nas entrevistas, apesar de, pelo menos inicialmente, tentar dissimular alguns sintomas segundo relato feito pelo cônjuge e por seu médico psiquiatra anterior.

De acordo com tais relatos, o caso parecia, à primeira vista, além de complexo e intrincado, de difícil manejo terapêutico. O diagnóstico ainda não havia sido estabelecido e a paciente continuava a manifestar alterações de comportamento aliada à falta de adesão ao tratamento proposto. Casada há cerca de dez anos, sempre se relacionara bem com o marido e se dedicava, além do trabalho, principalmente à família. Até então, era pessoa que nunca manifestara mudanças súbitas do humor ou agressividade; ao contrário, tratava-se de pessoa introvertida e discreta. No entanto, há cinco anos, começou a apresentar crises nas quais, subitamente, tornava-se hostil, ríspida e irritável, demonstrava suspeitas e medos infundados e era sujeita a explosões de raiva e choro sem motivos aparentes. Passava a desconfiar que o marido pretendia prejudicá-la e o acusava dramaticamente através de rompantes revestidos de 
uma teatralidade grosseira e vazia. Multiplicara vertiginosamente seus afazeres profissionais, por vezes viajava inesperadamente sem dinheiro e pertences, alegando compromissos de trabalho sem se preocupar em deixar avisos ou explicações. A casa vivia descuidada e a filha, praticamente abandonada, ressentia-se da falta da mãe. No mais, ostentava ora estranha taciturnidade, ora verbosidade despropositada e ressentida, com extrema instabilidade afetiva e mudanças bruscas do estado de ânimo.

M. permaneceu hospitalizada durante cerca de quinze dias e, nesse período, as inúmeras entrevistas que tivemos revelaram poucos dados psicopatológicos conclusivos. O discurso da paciente, assim como os seus relatos e respostas a algumas questões, mostravam-se, à primeira vista, aparentemente adequados e verossímeis como um todo, embora algumas assertivas não me convencessem definitivamente. Por exemplo, afirmava que trabalhava muito porque o casamento não estava bom e que tinha muitas ambições profissionais. É certo que estava procurando dissimular os sintomas através de racionalizações simples e singelas, mas, por outro lado, era evidente que não possuía um delírio de grandes proporções que pudesse lhe roubar completamente a autocrítica e comprometer irremediavelmente o seu juízo de realidade de forma duradoura. Tampouco vivenciava alucinações vívidas ou percepções delirantes típicas. Entretanto, à medida que ela se habituava às minhas visitas hospitalares, sentia-se mais à vontade para descrever, com detalhes, suas peculiares vivências anômalas. Depois que melhorou, disse que durante as crises tinha a impressão de que tudo se modificava. Notava que as pessoas começavam a olhá-la de maneira diferente, as fisionomias de algumas delas mudavam, colorindo-se de cores ameaçadoras e hostis. Entretanto, não conseguia identificar nisso uma intenção malévola bem determinada, limitando-se a vivenciar um verdadeiro turbilhão de sentimentos de temor e desconfiança que se dissipavam em seguida tão rapidamente quanto haviam surgido. Tudo lhe parecia distante e nebuloso, carregado de uma atmosfera opressiva e vagamente mágica. Por vezes, surgia-lhe na mente, tal qual um raio, a convicção súbita que sua vida corria perigo, que o marido poderia matá-la. Então, era tomada por um pavor intenso e saía de casa desabaladamente sem um destino certo. Parece que esse tipo de pensamento consistia numa espécie de juízo volátil e fugaz que se impunha à consciência mais pela sua própria intensidade do que pela solidez e consistência, até se converter em intuição débil e bruxuleante. Carecia, no entanto, da convicção íntima irrefutável e duradoura, própria dos verdadeiros juízos delirantes, assemelhando-se mais a raios cognitivos ocasionais que, vez por outra, fulguravam em sua consciência. Em outra ocasião, encontrando-se no interior de uma agência bancária, teve a forte impressão momentânea de que alguns avisos aos correntistas que se encontravam afixados nas paredes se referiam a ela mesma, que haviam sido ali 
colocados à guisa de "sinais" para ela, "avisando-a" de algo inefável e incompreensível. Saiu precipitadamente do local e, chegando à rua, reconsiderou, ainda atordoada, que poderia estar enganada, que tal impressão poderia ser fruto do nervosismo e da tensão constante de que era presa nos últimos dias. Contudo, não parou mais de pensar no ocorrido, considerando e reconsiderando ininterruptamente a verossimilhança ou não de sua experiência. Pode-se notar, neste exemplo, que falta à vivência anômala descrita um significado delirante específico que sempre é vinculado à percepção íntegra e que possui um caráter de 'revelação' quando se trata de autênticas percepções delirantes (Souza, 1998a; 2000a). Além disso, a crença íntima de M. em relação a ela mostrou-se volatilmente flutuante, dissipando-se após algum tempo.

Quanto aos antecedentes familiares, as informações eram que sempre denotou temperamento introvertido, sensível e delicado e, quando mais nova, fora menina muito tímida, assustadiça e impressionável, sujeita a desmaios diante de situações que provocassem fortes emoções. No início da vida adulta, tornou-se uma jovem solitária, contemplativa e idealista, com especial gosto para ideologias utópicas e extravagantes, dedicando-se a elas com um frêmito de fanatismo. O pai tinha recebido diagnóstico de transtorno afetivo bipolar (TAB)e sua irmã de anorexia nervosa.

Os exames complementares solicitados (química sanguínea TC do encéfalo) se mostraram sem alterações. Ela já havia se submetido a várias tentativas de tratamento psicoterápico analítico e utilizado, como tratamento farmacológico, alguns antidepressivos tricíclicos associados a benzodiazepínicos, mas nada havia acarretado melhora de seus sintomas. A remissão dos sintomas agudos e o controle temporário da irrupção das crises somente ocorreram após receber uma série de ECT (eletroconvulsoterapia) prescritas pelo seu médico um ano antes.

M. evoluiu clinicamente muito bem após a introdução de carbonato de lítio (900 mg/ dia) associado ao haloperidol (7 mg/dia, dose que posteriormente foi reduzida para $2 \mathrm{mg} /$ dia) não só durante sua internação, mas também depois, durante o tratamento ambulatorial. Viragens depressivas esporádicas que ocorreram tempos depois foram controladas de início com amitriptilina e, posteriormente, com fluoxetina. A paciente continuou o controle ambulatorial comigo e persiste até os dias de hoje, utilizando atualmente, com êxito, risperidona (3,0 $\mathrm{mg} /$ dia) associada a paroxetina $(20 \mathrm{mg} / \mathrm{dia})$, esquema terapêutico iniciado há aproximadamente quinze anos e que a tem protegido de outras crises semelhantes àquelas do passado. Continua trabalhando normalmente, separou-se do marido há muitos anos, reside sozinha e procura manter vida social satisfatória, saindo com amigas e relacionando-se esporadicamente com alguns namorados. 
A seguir, passarei à discussão do caso, a partir do qual proporei um novo conceito e, depois, ao estabelecimento da hipótese diagnóstica.

\section{Discussão do caso:}

Em seu dia a dia, M. Mostrava-se um pouco distímica, passiva e hipobúlica e, às vezes, aparentemente fria e distante. A vida social era restrita, limitando-se a relacionar-se com os pais e irmãos e, no trabalho, costumava se dedicar demasiadamente a certas tarefas que despertavam seu interesse. Analisando-se os seus antecedentes temperamentais e, levando em conta os dados colhidos durante o acompanhamento de sua evolução clínica em um período de cinco anos, podemos afirmar que ela possuía traços de personalidade esquizotípicos, ou seja, temperamento contemplativo, afetividade restrita e pouco expressiva, apego fanático a ideologias extravagantes, ansiedade social flutuante com tendência ao isolamento e "rapport" pobre (American Psychiatric Association, 1995) (Grupo 'A'/ Excêntrico ou Bizarro). Em contrapartida, suas crises agudas se sucediam de modo periodicamente fásico e foram muito bem controladas pelo carbonato de lítio, um potente estabilizador do humor. Ela apresentava sintomas afetivos, próprios das fases maníacas e (ou) hipomaníacas, tais como crises de cólera, hipercinesia, explosividade e inquietação. Além disso, havia uma predisposição familiar bem nítida para as desordens bipolares, além da excelente resposta do quadro clínico ao ECT. Entretanto, quando analisamos minuciosamente a essência fenomenológica das vivências anômalas da paciente, o resultado é que nos deparamos com material clínico difusamente esquizomorfo. Não é detectado, em nenhum momento, sentimentos ou ideias de grandiosidade, onipotência e autossuficiência, como seria de se esperar em um estado clássico de elação e expansão do humor. O que encontramos foi um turbilhão de sentimentos de suspeita, desconfiança e perplexidade diante de algo que se afigurava como uma profunda e inefável transformação do mundo e que vinham carregados de juízos auto-referenciais. À primeira vista, essas vivências anômalas se assemelhavam a ondas fugazes e breves que banhavam a consciência por um breve período de tempo e depois arrefeciam. Parece que, originariamente, correspondiam às chamadas ocorrências e percepções delirantes no sentido de Schneider (1968), mas que não se configuravam por inteiro, limitando-se a surgir de forma abortada e malograda.

Partindo-se do princípio de que a esquizotipia deve ser considerada um constructo clínico multidimensional complexo e variável (Kendler, Mc Guire, Gruenberg \& Walsh, 1995), pode-se concluir que, no caso em estudo, o comprometimento geral da personalidade não era por demais acentuado a ponto de acarretar um prejuízo social e ocupacional visivelmente incapacitantes. Entretanto, esses traços ou características esquizotípicas 
presentes na personalidade de $\mathbf{M}$. poderiam, e é esse o nosso pensamento, imprimir um colorido esquizomorfo (Souza, 1998a; 2000a) na fachada clínica final do quadro atípico. Assim, nisto residiria a essência fenomenológico-dinâmica (Souza, 1998a; 2000a). do modelo teórico de produção dos quadros de psicoses atípicas, de maneira geral. No caso em pauta, a desordem afetiva bipolar e (ou) mista, o verdadeiro "morbus" primário, ao incidir sobre o 'filtro' ou 'prisma' caracterológico esquizotípico, acionaria uma sequência de alterações fisiopatológicas secundárias, o "morbus" secundário, produzindo, desse modo, a morfologia clínica final, isto é, sintomas afetivos mesclados com sintomas esquizofreniformes frustros. Nossa longa e intensa experiência clínica com o manejo desses quadros faz-nos pensar que sua sintomatologia clínica poderia se originar da deflagração genética incompleta e malograda das duas entidades nosológicas que constituem os pilares da nosografia kraepeliana, ou seja, o grupo das "demências precoces" e o grupo da "insanidade maníacodepressiva"(Souza, 1998a; 2000a). As pesquisas, além de estudos clínicos e genéticos, a respeito da esquizotipia (Kendler, Mc Guire, Gruenberg \& Walsh, 1995) também nos induzem à convicção de que este transtorno abrange um amplo espectro de formas ou estados clínicos que poderíamos denominar "subprocessuais", considerando-se o termo "processo" no estrito sentido jasperiano (Jaspers, 1987). Assim, de um lado se situariam as formas subafetivas (Akiskal, 1994) e, de outro, as formas clínicas "subprocessuais". Na ocasião em que, na primeira dimensão fisiopatológica, houvesse uma ruptura do ponto de equilíbrio do "morbus" primário (ex: ativação de uma desordem bipolar), esta desencadearia uma ativação fisiopatológica extensa na segunda dimensão (disfunção caracterológica esquizotípica), originando-se os sintomas clínicos entrelaçados, como já vimos. Caso a condição esquizotípica "subprocessual" fosse dotada de potencial genético equivalente à condição afetiva ou "subafetiva", então as manifestações clínicas finais, decorrente da ruptura do ponto de equilíbrio simultâneo, provavelmente seriam de caráter esquizoafetivo clássico (Souza, 1998a; 2000a), ou seja, com uma distribuição mais ou menos equitativa dos sintomas psicopatológicos próprios das duas condições nosológicas e evolução clínica desfavorável. Como já dissemos antes, em relação a esse modelo teórico-conceitual que desenvolvemos - e nunca será demasiado repetir - é necessário visualizar o extremo dinamismo e o contínuo movimento que permeiam as modificações fisiopatológicas ao lado das fenomenológicas e que ocorrem a cada momento.

No que se refere às psicoses atípicas, cuja sintomatologia acabamos de analisar, o decurso clínico-evolutivo costuma ser favorável e benigno e as crises agudas, fugazes e passageiras. Podem ser consideradas, na verdade, formas clínicas psicoides (Souza, 1998a; 2000a), desde que se caracterizam por uma miscelânea psicopatológica frustra e malograda (o sufixo "oide" carrega o 
sentido de "aspecto ou forma de", "semelhante" e "relativo a"). Desse modo, finda a discussão teórica de nosso caso clínico, parece que já há condições para estabelecermos um padrão fenomenológico de atipicidade psicótica (Souza, 1998a; 2000a), tal como referido antes, e que se fundamenta nos seguintes critérios:

1- Os pacientes que apresentam quadros psicóticos atípicos geralmente possuem ou traços importantes ou transtornos completos de personalidade em um estágio pré-mórbido, com ênfase para o transtorno 'borderline' e esquizotípico da personalidade.

2- As vivências anômalas predominantes nos quadros psicóticos atípicos consistem, fenomenologicamente, em sintomas frustros, malogrados ou abortados de expressões psicopatológicas próprias e características de psicoses típicas e bem definidas, oriundas, por sua vez, de duas orientações endógenas básicas, seja esquizomorfa ou afetiva.

3- Os quadros psicóticos atípicos constituídos por vivências anômalas que apresentam intensa e dinâmica migração sintomatológica temporal, à semelhança de um verdadeiro polimorfismo "panneurótico", devem ser considerados nosologicamente pertencentes ao círculo das doenças afetivas (Souza, 1998a; 2000a).

Temos a convicção de que os critérios enumerados anteriormente podem ajudar o clínico a estabelecer um diagnóstico mais seguro e um tratamento mais efetivo desses quadros atípicos que, em nossa opinião, seriam melhor conceituados caso fossem denominados estados ou transtornos psicoides (Souza, 1998a; 2000a), considerando-se a sua natureza e características de acordo com o que foi discutido até aqui. Postulamos que esses quadros são o resultado da atividade de uma desordem afetiva bipolar ("morbus" primário) que, operando no 'filtro' caracterológico anômalo preexistente ("morbus" secundário), originaria a fachada clínico-fenomenológica final. Desse modo, essas entidades clínicas pertenceriam ao espectro das "psicoses do lítio" (Souza, 1998a; 1999; 2000a; 2000c), ou seja, seriam quadros clínicos que responderiam prioritariamente aos estabilizadores ou moduladores do humor. Já afirmamos em outra parte (Souza, 1998a; 2000a) que, longe de querer tumultuar a nomenclatura psiquiátrica com a adição desnecessária de mais um termo psicopatológico, temos certeza que tal denominação, ao contrário, poderia se prestar a homogeneizar e unificar um vasto território nosológico ainda relativamente desconhecido e inexplorado.Assim, para finalizar a discussão do caso clínico de M., estabeleceremos a sua hipótese diagnóstica de acordo com o que foi discutido e estabelecido até aqui. 


\section{Hipótese Diagnóstica:}

Transtorno psicoide em paciente com traços de personalidade prémórbida esquizotípicos. A figura 5, apresentada a seguir, pode facilitar a visualização esquemática dos principais conceitos teóricos aqui estabelecidos, além do registro gráfico sua interrelação dinâmica:

\section{Caso clínico 4 (fig. 5)}

Representação gráfica dos Transtornos Psicoides

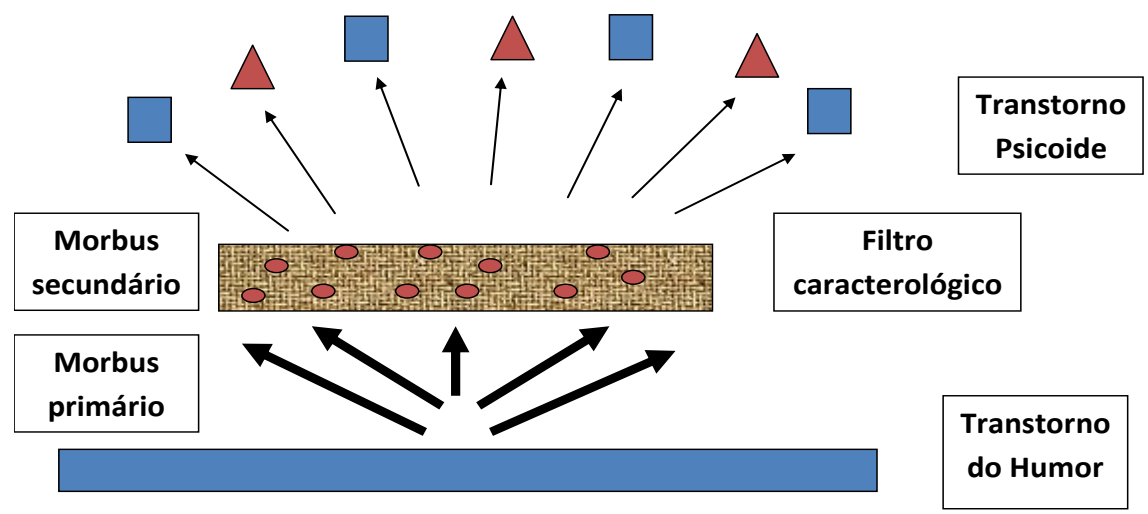

Outros exemplos podem ser resumidos para ilustrar o modelo de raciocínio clínico aqui desenvolvido, sempre enfatizando a distinção de dois grupamentos diagnósticos básicos:

Patoplastia (hipertrofia da psicopatologia prévia) X Estados ou Transtornos Psicoides.

TH (Transtorno do Humor ou Morbus Primário) + Transtorno ObsessivoCompulsivo de Personalidade (Morbus Secundário) $=$ Depressão Psicótica com delírios de prejuízo acompanhada de rituais obsessivo-compulsivos. Em alguns casos, observam-se sintomas (vivências) psicoides.

TH (Transtorno do Humor, Depressão Maior ou Morbus Primário) + Transtorno Evitativo de Personalidade (Morbus Secundário) $=$ Transtorno de Ansiedade Social Agudo.

TH (Transtorno do Humor, Episódio Maníaco ou Morbus Primário) + Transtorno Esquizotípico de Personalidade (Morbus Secundário) $=$ Transtorno Psicoide Esquizomorfo. 
TH (Transtorno do Humor, Episódio Maníaco ou Morbus Primário) + Transtorno Histriônico de Personalidade (Morbus Secundário) = Transtorno Dissociativo e (ou) Comportamental grave persistente e refratário.A utilização de moduladores do humor muito raramente é cogitada, embora haja, em muitos casos, acentuada hipercinesia, comportamento auto-destrutivo e frequentes abusos de benzodiazepínicos e outras substâncias psicoativas ao lado de padrões histriônicos comportamentais exagerados e amplificados.

TH (Transtorno do Humor, Depressão Maior ou Morbus Primário) + Transtorno Histriônico de Personalidade (Morbus Secundário) = Depressão 'Dramática' e refratária.Raramente, o referido transtorno de personalidade é considerado como fator agravante e de resistência ao tratamento instituído.

Estes e outros exemplos, muitos dos quais poderão ser retirados do próprio acervo de pacientes dos leitores, servirão ao exercício do padrão de raciocínio clínico proposto neste texto. Essas concepções teóricas talvez possam ajudar o raciocínio clínico na formulação diagnóstica na prática médica do dia a dia e, consequentemente, facilitar a adoção precoce de terapêuticas capazes de aliviar os sintomas de pacientes acometidos de transtornos psiquiátricos complexos e resistentes. É nossa opinião que somente através da apresentação detalhada de casos clínicos e sua discussão criteriosa, poderemos esclarecer muitos pontos obscuros inerentes às fronteiras nosológicas em psiquiatria, contribuindo, desse modo, para dissipar uma visão involuntariamente estática e compartimentada do adoecer psíquico.

\section{Referências bibliográficas:}

Akiskal, H.S. (1992). Delineating Irritable and Hyperthymic Variants of the Cyclothymic Temperament. J Pers Disorder 6, 326-342.

(1994). The Temperamental Borders of Affective Disorders. Acta Psychiatrica Scandinavica, 89 (Suppl 379), 32-37.

Akiskal, H.S. \& Mallya, G. (1987). Criteria for the Soft Bipolar Spectrum: Treatment Implications. Psychopharmacol Bull, 23, 68-73.

American Psychiatric Association. (1995). -DSM-IV -Manual de Diagnóstico e Estatística de Transtornos Mentais. Porto Alegre, Editora Artes Médicas, $4^{\mathrm{a}}$ edição. 
(1989). DSM-III-R - Manual de Diagnóstico e Estatística de Transtornos Mentais. São Paulo, Editora Manole, $3^{\mathrm{a}}$ edição.

Cloninger, C.R. , Svrakic, D. M. , \& Przybeck, T. R. (1993). A psychobiological model of temperament and character. Archives of General Psychiatry, 50, 975-990.

Cloninger, C.R., Przybeck, T. R., \& Svrakic, D. M. (1991). The tridimensional personality questionnaire: U.S. normative data. Psychological Reports, 69, 1047-1057.

Jaspers, K. (1987). Psicopatologia Geral, Livraria Atheneu, Rio de Janeiro.

Kendler, K.S.; Mc Guire, M; Gruenberg, A.M.; Walsh, D. (1995). Schizotypal symptoms and signs in the Roscommon Family Study, their factor structure and familial relationship with psychotic and affective disorders. Arch Gen Psychiatry 52 (4), 296-303.

Kretschmer, E. (1954). Psicologia Médica. Barcelona, Editorial Labor.

Livesley WJ, Jackson DN, Schroeder ML. (1992). Factorial structure of traits delineating personality disorders in clinical and general population samples. J Abnorm Psychol, 101, 432- 440.

Marneros, A. (2001). Origin and Development of Concepts of Bipolar Mixed States. Journ Affective Disorders, 67, 229-240.

Paris, J. (1996). Significance of Biological Research for a Biopsychosocial Model of the Personality Disorders. In: Silk, K.R.(org.) Biology of Personality Disorders. Washington D.C.

Schneider,, K. (1968). Psicopatologia Clinica. São Paulo, Editora Mestre Jou.

Souza, G.F.J. (1990). The Endogenous Psychoses: A Phenomenological-Dynamic Approach. Belo Horizonte, Biblioteca da Universidade de Heidelberg, Alemanha.

(1998a Junho).A Fenomenologia dos Transtornos Psicóticos Atípicos - Os Estados Psicoides. Revista de Psiquiatria Biológica, 6 (2), 99-106.

. (1998b Dezembro). A Fenomenologia das Vivências Delirantes: Dois Casos Clínicos. Revista de Psiquiatria Biológica,6 (4), 201-210.

(1999 Setembro). Uma Interpretação Dimensional dos Transtornos Psicóticos: da Tipicidade à Atipicidade.Revista de Psiquiatria Biológica, 7 (3), p.133-142.

(2000a).The Phenomenology of Atypical Psychotic Disorders: The Psychoid States. Neurology, Psychiatry E Brain Research, 7 (4), 151-156.

(2000b).The Phenomenology of Delusional Experiences: Two Clinical Cases. Neurology, Psychiatry E Brain Research, 8 (2), 81-88. 
- (2000c). A Dimension Interpretation of Psychotic Disorders: From Typicality to Atypicality. Neurology, Psychiatry \& Brain Research, 8 (3), 131-138.

Svrakic, D. M.; Whitehead, C.; Przybeck, T. R.; Cloninger, C. R. (1993). Differential diagnosis of personality disorders by the seven-factor model of temperament and character. Arch Gen Psychiatry, 50 (12), 991-9. 